\title{
SOMOS TODOS AMERICANOS? UNIDADE E DIVERSIDADE REGIONAL NAS AMÉRICAS
}

\author{
WE ARE ALL AMERICANS? \\ UNITY AND REGIONAL DIVERSITY IN THE AMERICAS
}

\author{
Eli Alves Penha ${ }^{(*)}$ \\ Universidade do Estado do Rio de Janeiro, Rio de Janeiro (RJ), Brasil
}

Resumo: O texto analisa os discursos e projetos de unidade continental, colocando em questão a pertinência da construção de uma identidade comum, a partir da noção de "americanidade". A "americanidade" e suas diferentes dimensões regionais serão aqui investigadas considerando dois níveis de análise. O primeiro nível abarca a formação étnica das sociedades americanas, considerando as matrizes europeia, ameríndia e africana. O segundo nível de análise detém-se na regionalização do continente, procurando identificar alguns pontos de convergência sociopolíticas, apesar dos movimentos de fragmentação produzidos por fatores geopolíticos e ideológicos.

Palavras-chaves: Geografia Política; Pan-americanismo; Regionalização.

Abstract: This paper discuss the speeches and projects about the continental unity, calling into question the relevance of building a common identity based on the notion of "Americanidade". "Americanidade" and its various regional dimensions are investigated here considering two levels of analysis. The first, concerns the ethnical formation of American societies, considering the composition formed by Europeans, Amerindians and Africans people. The second level of analysis holds in the regionalization of the continent, seeking to identify the points of convergence for continental unity, facing the fragmentation of movements produced by geopolitical and ideological factors.

Key Words: Political Geography; Pan-Americanism; Regionalization.

$(*)$ Doutor, Professor do Instituto de Geografia da Universidade do Estado do Rio de Janeiro; Analista do Instituto Brasileiro de Geografia e Estatística. E-mail: <elialvespenha@hotmail.com>. Recebido em: 03.02.2015; aceito em 07.06.2015. 


\section{INTRODUÇÃO}

"Somos todos americanos. (..) Hoje a América escolhe cortar os grilhões do passado para buscar um futuro melhor para o povo cubano, para o povo americano, para nosso hemisfério inteiro e para o mundo."

O discurso acima, proferido em 17 de dezembro de 2014 pelo Presidente dos Estados Unidos Barack Obama por ocasião do reconhecimento diplomático do regime cubano, revelou também o interesse de seu governo em buscar maior sinergia política com os países da América Latina. A frase dita em espanhol, "somos todos americanos", ressoou positivamente em todo o continente fazendo ecoar o reconhecimento de uma identidade comum, forjada no contexto das lutas de libertação nacional do jugo colonial europeu.

De fato, se, no passado, o uso do termo "americano" era muito usado para designar todos os nativos e os nascidos no continente, na atualidade, ele é adjetivado porque pode ter muitas conotações: latino-americanos, hispano-americanos, luso-americanos, anglo-americanos etc. Isoladamente, o termo América hoje em dia é referido aos estadunidenses, quase que exclusivamente.

Desde a chegada de Cristóvão Colombo, o conceito de América sofreu diferentes interpretações segundo a visão e o sentido que o colonizador europeu atribuiu em cada momento ao continente. No contexto das independências dos países americanos, verificou-se o resgate do sentido positivo da ideia de América, fundamentado no esforço de intelectuais e políticos das novas nações.

Nessa direção, o Presidente Thomas Jefferson (1801-1809) criou o conceito de Hemisfério Ocidental, baseado na peculiaridade dos "modos de vida" dos povos americanos que os distinguiriam do resto do mundo. Também Simón Bolívar (1783-1830) e demais lideranças hispano-americanas valorizaram o caráter superior da condição de americano. Nesse contexto, pela primeira vez, a América foi definida a partir da visão de seus habitantes, ainda que a Europa continuasse sempre como referência (SANTOS, 2014).

Note-se que, nesse contexto histórico, havia também predileção pelo termo "Colômbia" ou "Columbia" em inglês, numa clara homenagem à Cristóvão Colombo. Nos Estados Unidos, por exemplo, Philip Morin Freneau (1752-1832), também conhecido como o poeta da revolução americana, em um poema intitulado "A Balança Política", chegou a declarar "A Columbia jamais será governada por uma ilha”, fazendo referência à luta da nova nação contra o domínio colonial inglês. Apesar de não ter vingado como nome do país, o termo "Columbia" foi disseminado na costa leste dos Estados Unidos designando o distrito da capital do país, algumas cidades, empresas e até uma antiga universidade fundada no século XVIII (PATTEE, 1902).

O topônimo também foi utilizado por Simon Bolívar (1773-1830). Em 1815, teria escrito "A Nova Granada se unirá com Venezuela, se conseguirem formar uma república central... Esta Nação se chamará Colômbia como um tributo de justiça e gratidão ao criador de nosso Hemisfério de Colombo" (BOLÍVAR, sd.). 
No entanto, foi a Doutrina Monroe que consagraria o termo "América" como espaço de luta pela liberdade dos povos do continente. Apresentada ao Congresso dos Estados Unidos em 1823 pelo Presidente James Monroe (1817-1825), a doutrina ficou famosa pela frase "A América para os americanos", que propugnava pela não intervenção europeia nos assuntos internos dos países americanos e contra a criação de novas colônias no continente.

Para os líderes políticos dos demais países do continente, a Doutrina Monroe foi um mero expediente de dominação e controle geopolítico. De um lado, embalada pela ideia do "destino manifesto" justificou que os Estados Unidos continuassem a expandir suas fronteiras na direção do oeste, dizimando as tribos indígenas que lá habitavam e se apropriando dos territórios do México, ricos em recursos minerais; de outro, ajudou a disseminar a ideia de superioridade civilizacional dos Estados Unidos perante os seus vizinhos.

Essa pretensa superioridade tinha que ver com a força de suas instituições democrático-liberais e aos aspectos étnicos e culturais, como a herança anglo-saxã de confissão calvinista, em detrimento da cultura índia, mestiça e católica das sociedades ibero-americanas. Somados, tais fatores ajudariam a explicar o progresso estadunidense em detrimento do atraso latino-americano.

Segundo Gilberto Freyre, as diferenças existentes entre as sociedades americanas reflete a própria formação geopolítica do continente. Constituída de ilhas sociológicas de colonização inglesa, espanhola, portuguesa, estas sociedades sempre manifestaram interesses irreconciliáveis, permeados por conflitos de toda ordem. Segundo ele, a América nasceu e se formou sociologicamente como um grupo de ilhas que, por motivações de natureza econômica foram se agrupando em ilhas maiores ou menores por meio de confederações como a anglo-americana, ou de reinos ou impérios como o luso-brasileiro, ou repúblicas como hispano-americanas, de modo que dentro da configuração continental o dado permanente é a diversidade sociológica formando verdadeiras ilhas (FREIRE, 2003).

Por outro lado, não se pode deixar de notar as profundas transformações sociopolíticas ocorridas no continente desde a última década, na qual o próprio Barack Obama, como primeiro presidente afrodescendente dos Estados Unidos, é um dos principais resultados.

Nessa mesma direção, menciona-se o movimento bolivariano liderado por Hugo Chaves e seu sucessor Nicolas Maduro na Venezuela que, junto com Rafael Corrêa do Equador e Evo Morales da Bolívia, são os mais influentes expoentes de uma nova geração de governantes populares de origem mestiça e indígena. Morales, eleito em 2005, é reconhecidamente o primeiro chefe de Estado eleito como representante legítimo da comunidade indígena do seu país e que, simbolicamente, passou também a representar toda a população ameríndia do continente.

Outros exemplos notáveis destas transformações sociopolíticas foram as eleições do líder sindicalista Luiz Inácio Lula da Silva e da ex-guerrilheira Dilma Roussef no Brasil, o casal Nestor e Cristina Kirshner, na Argentina e Michele Bachelet, no Chile, que se destacam pelo desenvolvimento de políticas governamentais com forte conteúdo 
social. Nesse sentido, aparecem como verdadeiros representantes de grandes estratos da população até então invisíveis no panorama político do continente; emersos da "América profunda" para assumirem a condução dos seus respectivos governos nacionais.

Considerando a convergência destes movimentos sociopolíticos, inéditos na história do continente, o presente texto pretende colocar em discussão a pertinência da construção de uma identidade comum a todos os "americanos" a partir da noção de "americanidade". Entendida aqui como "uma dimensão mais ampla de partilha de identidades que se abre em outras leituras possíveis da questão da integração continental" (CUCCIOLETTA, 2001, p. 03), a "americanidade" apresenta-se diferenciada regionalmente, o que será investigado nesse texto a partir de dois níveis de análise.

O primeiro diz respeito à formação cultural das sociedades americanas, considerando a composição étnica formada a partir das matrizes europeia, ameríndia e africana. O estudo do antropólogo brasileiro Darcy Ribeiro (1983) sobre as "Três Américas" ("povos testemunhos", "povos transplantados" e "povos integrados") será utilizado como ferramenta analítica para uma melhor compreensão do tema.

O segundo nível de análise detém-se no processo específico de regionalização do continente. A obra de Wladimir Lênin, "As três fontes constitutivas do marxismo" (2015), será utilizada como referência metodológica para entender algumas características sociopolíticas peculiares das sociedades americanas. Nesse estudo, Lênin analisa a contribuição teórica da filosofia idealista alemã, da economia política inglesa e da ciência política francesa para a concepção de uma unidade continental europeia, pautada na luta de classes e orientada para a revolução socialista (LÊNIN, 2015). O interesse em transpor esse modelo teórico para o continente americano é meramente um exercício de regionalização do continente, pautado na validade de buscar uma identidade comum diante dos movimentos de fragmentação produzidos por fatores geopolíticos e ideológicos.

$\mathrm{Na}$ primeira parte do texto, discuto os projetos de unidade continental a partir das formulações de Monroe e Bolívar. Na segunda parte, apresento uma proposta de regionalização do continente considerando as contribuições teóricas de Darcy Ribeiro e Wladimir Lênin. O ponto de convergência é a relevância da construção de uma identidade comum, centrado no significado de "América" como construção dos povos emancipados do continente.

\section{A "AMÉRICA" E OS PROJETOS DE UNIDADE CONTINENTAL}

Na narrativa do filme "América" (1924) dirigido por David Griffith, a independência dos Estados Unidos é contada enaltecendo-se a noção de "América" como um projeto político, de caráter endógeno, criado pelo novo "homem americano" que nasce deste processo. No filme, Griffith mostra que o processo de ruptura ocorreu exclusivamente com o consórcio dos próprios habitantes das treze colônias, sem participação dos "ameríndios" nativos e dos negros que não tinham direitos políticos reconhecidos, pois eram escravizados.

Esse aspecto escravagista ajuda a explicar porque os Estados Unidos, sob o governo de Thomas Jefferson, recusaram-se a reconhecer a República do Haiti, a segunda 
colônia europeia a se tornar independente no continente. Instituída em 1804, depois de uma década de batalhas sangrentas contra tropas francesas, os revolucionários haitianos eram formados por escravos africanos que, ao assumiram o poder, instalaram o primeiro Estado negro da América. Por conta de seu perfil antiescravocrata e por pressão de seu aliado francês, os Estados Unidos só viriam a reconhecer o país sessenta anos depois, já no contexto da guerra civil de 1861 a 1865 (PINHEIRO, 2014).

Sob esta ótica, a noção de "América" surge nos Estados Unidos como um projeto exclusivo dos antigos colonizadores brancos, de origem britânica e de formação protestante e dispondo de um vasto fundo territorial a ser explorado e ocupado. A própria ideia de "fronteira em movimento" ou o "destino manifesto" em direção ao Oceano Pacífico fortaleceu essa concepção expansionista e de "liberdade", no sentido da constituição de um espaço elástico e prospectivo (TURNER, 1996). Essas características também contribuíram para forjar o sentido de identidade nacional do povo estadunidense em que os Estados Unidos da América passam a ser a expressão máxima do "novo mundo" que ressurge sem a tutela europeia e, ao mesmo tempo, como sinônimo de liberdade e de progresso.

A derrota da esquadra espanhola no mar do Caribe para os estadunidenses, em fins do século XIX, propiciou uma maior correlação entre o país (EUA) e a nacionalidade (americano), já que mais uma vez os europeus são derrotados, reafirmando-se os propósitos da Doutrina Monroe.

Contudo, a atuação dos Estados Unidos na defesa e difusão dos ideais de liberdade e progresso em todo o continente, muito aquém de representar a afirmação de um sentimento de "americanidade" - de comunhão de valores comuns no espaço continental -, foi visto por muitas lideranças de países americanos como um mera "americanização" do continente. Compreendida esta como mera imposição dos valores da sociedade estadunidense.

\subsection{SIMÓN BOLÍVAR E A HISPANO-AMÉRICA}

Uma das principais lideranças que se opuseram à Doutrina Monroe foi Simón Bolívar. Nascido em Caracas na Venezuela em 1773, liderou o movimento de libertação de cinco países submetidos ao domínio espanhol: Venezuela, Colômbia, Bolívia, Peru e Equador, por isso, é chamado de "pai da independência sul-americana". A meta de Bolívar era criar os Estados Unidos Meridionais, reunidos em uma confederação que ia do México até a Argentina, para se opor aos Estados Unidos Setentrionais.

Na célebre Carta da Jamaica de 1815, Simón Bolívar foi bem claro no seu desejo de formar uma confederação hispano-americana com as regiões que anteriormente pertenciam ao Império Espanhol, baseado no fato de elas terem um passado histórico em comum, as mesmas instituições, professarem idêntica religião - a católica, e terem o espanhol como a sua língua dominante. Neste seu projeto, que podemos considerar como um esboço da futura união latino-americana, ficavam de fora os Estados Unidos, (por serem de fala inglesa e de fé majoritariamente protestante, além de inclinados ao expansionismo), o Haiti (porque falava francês) e o Brasil (que na época ainda não 
proclamara a independência). Na prática, conseguiu criar a República da Grã-Colômbia da qual foi Presidente de 1819 e até a sua morte em 1830, quando a mesma fragmentou-se em três unidades políticas menores: Equador, Colômbia e Venezuela.

Para muitos historiadores, a ideia de se criar uma confederação hispano-americana fracassou pela oposição surgida entre Bolívar e o General San Martin - responsável pela libertação na Argentina, Chile e Peru. San Martin era contrário à ideia de República e preferia o modelo de Império na América Hispânica, pois, para ele, a situação rural na região favorecia o secesionismo e, portanto, conspirava contra a unidade do continente. Essa posição de San Martin, aliada à indefinição da posição do Peru na composição da confederação hispano-americana, desagradou a Simón Bolívar. O desentendimento gerado por essas questões, ficou patente no encontro que tiveram em Guaiaquil, no Equador, em 26 de junho 1822 e que resultou no fim do projeto de unidade continental.

Todavia, isso não o impediu de organizar o Congresso do Panamá em 1826, com a finalidade de criar um sistema interamericano de defesa. Para muitos analistas, este congresso pode ser apontado como um dos marcos doutrinários do pan-americanismo, porque consagrou princípios que seriam posteriormente muito utilizados pelo sistema interamericano e mundial, como a Organização dos Estados Americanos e a Sociedade das Nações de Woodrow Wilson (ALEIXO, 2000, MENEZES, 2007). O tratado resultante do Congresso, no entanto, foi ratificado apenas pela Colômbia, Equador, Panamá e Venezuela, integrantes da Grã-Colômbia (MENEZES, 2007:70).

O projeto político de Bolívar encontrou adversários em duas frentes. No plano interno, o seu objetivo de acabar com os privilégios de uma classe e trabalhar pela liberdade e igualdade com as classes menos abastadas, colocou-o em conflito com os "criollos”, cujos interesses particularistas e locais se posicionavam favorável à fragmentação política (PRADO, 1981, p. 26). No plano externo, menciona-se o papel exercido pela Inglaterra e Estados Unidos que incentivavam as divisões sociais internas como forma de enfraquecer o projeto de Bolívar, na hipótese de que a emergência de um Estado Hispânico forte e poderoso pudesse prejudicar seus interesses comerciais e econômicos na região.

O projeto de Bolívar, apesar de fracassado no seu objetivo principal de unidade política na América Hispânica, influenciaria várias iniciativas com vistas à formação de blocos regionais, tais como os propostos pelo México, entre 1830 e 1840. Contudo, a guerra desse país contra os Estados Unidos, deflagrada pela anexação do Texas (18461848), enfraqueceu a posição mexicana e transferiu a iniciativa para a América do Sul nas décadas seguintes. A realização dos congressos de Santiago (1856) e o de Lima (1848 e 1864-1865) perseguiram este objetivo, porém, sem alcançar resultados práticos. Os Estados Unidos e o Brasil foram excluídos desses congressos: o primeiro, por conta de seu expansionismo territorial e o Brasil, por conta de seu intervencionismo na região do Prata, prática esta considerada contrária à solidariedade continental (TUNER, 1893, p. 77).

Na segunda metade do século XIX, a expressão "América Latina" se consolida como manifestação da oposição em relação à América Anglo-Saxônica, representada pelos Estados Unidos e seus interesses de domínio continental. O termo, em verdade, expressou um movimento conjunto: a iniciativa francesa de se aproximar dos "latino-americanos", 
isolando os ingleses e estadunidenses ao invadir o México em 1867 e, posteriormente, agregando o Haiti e o Brasil à Ibero-América. De qualquer modo, a noção de América Latina passa a prevalecer como um aspecto estrutural da clivagem continental.

Sob essa ótica, o termo "América Latina" passou a ser visto como forma de resistência e também como baluarte para justificar os interesses irreconciliáveis com a América Anglo-saxônica, sobretudo a partir do "Corolário Roosevelt" e sua política de intervencionismo na América Central e Caribe. Também conhecida como "o corolário Roosevelt da Doutrina Monroe", a nova doutrina estratégica formulada pelo Presidente Theodore Roosevelt em 1904 defendia o direito dos Estados Unidos de empreenderem ataques preventivos contra estados que se mostrassem "ineficientes" do ponto de vista de sua ordem interna, ou que ficassem "inadimplentes" do ponto de vista de suas dívidas externas.

\subsection{A DOUTRINA MONROE E A ORGANIZAÇÃO DO PAN-AMERICANANISMO}

O esvaziamento dos movimentos hispano-americanos, em fins do século XIX, reanimou os interesses estadunidenses de promoverem uma maior integração no continente respaldado pela sua ascensão como grande potência econômica. Ancorado na Doutrina Monroe, os Estados Unidos definem uma estratégia de integração continental denominada por eles de pan-americanismo.

Em consonância com os movimentos pan-germânico e pan-eslávico, o pan-americanismo foi um princípio que defendia a aproximação cultural, política, econômica e comercial entre os países do "Novo Mundo", como forma de preservar a solidariedade e a integridade continental contra qualquer ingerência de potências externas ao continente. Diferente do ideal pan-americanista de Bolívar, que propugnava por uma solidariedade continental por um movimento conjunto de países, o pan-americanismo de Roosevelt apresentava-se de forma unilateral, exprimindo as potencialidades da economia dos Estados Unidos como substituto dos capitais europeus no continente.

Para o Brasil, o pan-americanismo, além de reforçar uma tendência de aproximação com os Estados Unidos que já vinha se delineando ainda no final do Império, permitia abrir as portas para um melhor entendimento diplomático do país com todas as repúblicas americanas. Na perspectiva do Barão de Rio Branco, então chanceler do Brasil, o pan-americanismo foi um expediente importante usado para dirimir os conflitos fronteiriços com os países vizinhos, no contexto de demarcação das fronteiras, além de aumentar a influência geopolítica do Brasil na região.

As outras nações da América Latina reagiram de diferentes formas ao princípio pan-americanista. De um lado, o ativismo diplomático da Argentina, estimulado pela sua opulência econômica, procurava se consolidar como potência regional incrementando suas relações com os países do continente americano, a nível bilateral e multilateral; por outro, os outros países, por sua vez, buscavam definir princípios de convivência política e jurídica, ante a nova postura dos Estados Unidos com suas políticas intervencionistas no Caribe e na América Central (PECEQUILO, 2003, p. 85).

$\mathrm{Na}$ prática, o pan-americanismo concretizou-se pelas diversas conferências, que preconizavam o estabelecimento de planos de arbitragem e solução pacífica de quais- 
quer disputas entre as nações americanas, bem como possibilitar melhorias nas relações comerciais. A primeira conferência foi em Washington (1889-90), onde os Estados Unidos apresentaram a proposta de um pacto aduaneiro, onde caberia aos norte-americanos aplicar e recolher as tarifas comerciais dos países do continente (ALVES JÚNIOR, 2015).

Outras conferências ocorreriam ainda na Cidade do México (1901-2), no Rio de Janeiro (1906), em Buenos Aires (1910) e em Havana (1928). A conferência de Petrópolis (1947), que criou o Tratado Interamericano de Assistência Recíproca (TIAR) e a de Bogotá (1948), que originou a Organização dos Estados Americanos (OEA), foram exemplos definitivos da determinação dos Estados Unidos em liderar o processo de união interamericana e, ao mesmo tempo, de exercer influência geopolítica decisiva nos assuntos continentais.

A iniciativa pan-americanista empreendida pelos Estados Unidos foi e tem sido respaldada por convergências de interesses econômicos e ideológicos de longo prazo, cujos exemplos mais recentes foram a Aliança para o Progresso empreendida na década de 1960 por John Kennedy e a Associação de Livre Comércio da América, conhecida pela sigla ALCA, empreendida pelo governo de George W. Bush, nas décadas de 1990/2000.

Em oposição à ALCA, os países latino-americanos procuraram se organizar em diversas associações das quais a mais combativa foi o movimento bolivariano reunido em torno da Aliança Bolivariana para os Povos da Nossa América - Tratado de Comércio dos Povos (ALBA). Criado como meio de resgatar a dívida social das populações indígenas e mestiças que estiveram sempre marginalizadas do processo de desenvolvimento econômico, o movimento bolivariano, liderado por Hugo Chaves e Evo Morales, surge como franca oposição ao chamado "imperialismo ianque", reforçando a fragmentação do continente em torno de dois campos de força ideológica. Em contrapartida, ao fazer referência aos direitos históricos dos povos indígenas, evidencia a construção da etnicidade enquanto categoria política (ZARUR, 2005).

\section{AS QUATRO DIMENSÕES DA AMERICANIDADE}

Segundo Alfredo Bosi (1981), a oposição ao velho colonialismo de um lado, que propiciou a instauração da república no continente e, de outro, ao novo imperialismo que fundou a América Latina enquanto conceito e valor, comporta diferenças sensíveis quando se comparam às diversas nações que a integram (BOSI, 1981). Mas como interpretar essas diferenças?

Uma explicação está no modelo de organização institucional. Nesse sentido, enquanto os Estados Unidos conservaram o modelo inglês de um estado, vários povos e nações, o Brasil procurou preservar o paradigma de um só povo, nação e estado, inspirado no modelo republicano francês. Na América Hispânica, por sua vez, várias situações vão coexistir: desde o sistema de segregação herdado dos espanhóis, como se observa nas populações indígenas dos altiplanos; até as áreas de "plantations" como na Colômbia, Cuba e Venezuela, cujo modelo está mais próximo dos brasileiros. Podemos caracterizar essas diferenciações em quatro dimensões regionais, segundo suas peculiariedades sociopolíticas mais marcantes. 


\subsection{A "ECONOMIA DE MERCADO" DO MULTICULTURALISMO ESTADUNIDENSE}

No final do século XIX, a imagem projetada pelos Estados Unidos no mundo como a terra da liberdade e do progresso material atraiu uma grande variedade de povos da Europa assimilados pelos ideais de democracia, progresso, valores éticos e religiosos, ditados pelos "founding fathers" anglo-saxões, denominados "wasp" (white, anglo-saxões, protestant people). Somados aos índios e negros que lá viviam contribuíram para formar o caldo cultural, denominado por eles de "melting pot".

Na visão deles, a América (EUA) era a síntese do "homem novo", amante da liberdade, do progresso, e ciente dos seus direitos individuais; era a terra de imigrantes e de minorias que se enquadravam nesta fórmula do bem-estar coletivo. É desta forma que os Estados Unidos se apresentaram para o mundo, como exemplo de assimilação de "raças". A partir do momento que esta autoimagem se mostrou uma farsa, sobretudo em relação aos negros, o discurso passou a ser a difusão da imagem de uma sociedade integrada, em termos dos valores, que englobava a diversidade étnica e cultural (SMITH, 1994, p. 185).

A partir da segunda metade do século XX, o progresso material e a intensa difusão, pelos meios de comunicação do "modo de vida americano" como terra das oportunidades, do "self made man", propiciou uma enorme movimentação de pessoas das regiões da América Latina e da Ásia em direção aos Estados Unidos, num dos períodos mais longos e sustentados de migração "espontânea" da história do país. Uma das consequências dessas migrações foi a mudança drástica na "mistura étnica" da população dos Estados Unidos, formando grandes "encraves" minoritários que, somados aos já existentes no interior da sociedade americana, levou a uma pluralização de culturas nacionais e de identidades nacionais.

A lógica de "um Estado, vários povos e nações" consubstanciou-se na ideia de "multiculturalismo", difundido por alguns setores políticos como forma de garantir o ingresso destes segmentos no conjunto da sociedade. São exemplos: as cotas raciais e a criação de mercados específicos para estes novos segmentos, formando um moto contínuo de absorção, segregação e integração social, mediante uma perspectiva de mercado étnico e cultural (HALL, 1999, p. 82).

O multiculturalismo, construído a partir da premissa de que cada "raça" possui uma cultura e uma visão de mundo, transformou-se em um conceito central do discurso político dos Estados Unidos. Ele permite definir um equilíbrio ou um armistício entre os grupos étnicos e os setores sociais que compõem o conjunto da sociedade estadunidense. O mercado aparece como o elemento estabilizador e integrador entre os vários grupos, cabendo ao Estado, garantir a coesão interna a partir de seu apoio à diversidade. Ao valorizar os aspectos econômicos das relações sociais em correspondência aos processos de integração econômica global, o multiculturalismo se transforma na tradução para a etnicidade do neoliberalismo econômico (ZARUR, 2006, p. 02-03).

\subsection{A "HISTÓRIA" DOS POVOS TESTEMUNHOS}

Na concepção de Darcy Ribeiro, a formação dos “povos testemunhos” foi construída tendo como parâmetro principal os laços identitários anteriores à colonização europeia. 
O México - e a civilização Asteca - e o Peru - e a civilização Inca - seriam os dois arquétipos deste modelo. Formados essencialmente por povos de origem pré-colombianas, estas sociedades estão premidas entre a tradição e a modernidade de uma forma mais explícita e dramática que as verificadas nos outros modelos de formação nacional. As minorias étnicas destes países, mais vinculadas aos ambientes europeus e norte-americanos incorporam a modernidade e os seus ideais de maneira mais intensa. Essa minoria, adestrada e preparada para os valores prevalecentes da cultura ocidental moderna, consome com voracidade os valores da modernidade: o mercado e a liberdade. As populações indígenas, caboclas, mulata e negra, erram pelo mundo rural e pelas periferias das grandes cidades à deriva da economia de subsistência e marginal na economia de mercado (ORTIZ, 1993).

A falência do modelo neoliberal na América Latina e os seus resultados sociais dramáticos deram margem para o surgimento de movimentos indigenistas, sobretudo no México e na Bolívia. Sobre este aspecto, cumpre destacar a eleição, em janeiro de 2006, do líder cocaleiro e indígena Evo Morales para Presidente da República da Bolívia.

A eleição de Morales foi resultado de transformações econômicas, políticas e culturais que teve início na segunda metade do século XX na Bolívia. Nesse contexto, formulou-se um pensamento indígena fortemente étnico, que passou a ter um papel preponderante nas lutas dessas populações por mudanças institucionais que reconhecessem suas identidades culturais. Uma das conquistas mais recentes e mais importantes foi o reconhecimento do "plurinacionalismo" da Bolívia no qual todas as 36 etnias indígenas passaram a ser reconhecidas como nações integrantes do Estado boliviano. Essa foi uma conquista do movimento indígena que luta por suas formas de viver e se identifica, antes de tudo, enquanto indígena ou originário, como muitos preferem ser identificados (FREITAS, 2012).

Na Venezuela, Hugo Chávez é eleito pela primeira vez em 1998 e assume, como principal item de sua política exterior, a construção de uma União Latino-Americana inspirada nos ideias de Simón Bolívar. Com a morte de Chaves, em 05 de março 2013, o seu sucessor, Nicolas Maduro, torna-se, desde então, o principal divulgador das ideias bolivarianas no continente. O denominador comum entre ambos é um projeto político de integração continental, de cunho nacionalista e socializante, de valorização das culturas locais e dos povos indígenas da América, ou seja, a valorização da História dos povos testemunhos da América pré-colombiana.

\subsection{A "CULTURA" DOS POVOS TRANSPLANTADOS}

As sociedades "transplantadas", tal como denominada por Ribeiro (1983), se manifestam nos territórios onde o processo de colonização apresentou a origem nacional predominante dos povoadores. A Jamaica e o Haiti, com a imigração forçada dos negros africanos e a Argentina e Uruguai, com o elemento europeu, seriam os exemplos mais expressivos deste modelo. No caso destes dois últimos, o progresso foi sustentado pelas atividades agroexportadora e a vida social reproduziu o estilo de vida europeu nas suas cidades. Os índios e os mestiços ficaram alijados deste processo de modernização e tornaram-se "invisíveis" na difusão da imagem que se projetou destes países. 
A crise econômica que assolou a Argentina, no início da década de 2000, foi um exemplo dramático de que como a crise econômica tende a invadir outros segmentos da vida social do país, tanto do ponto de vista institucional, como cultural. Aí cabe mencionar a quantidade de cidadãos argentinos que buscam solução para a crise se apegando a valores culturais de caráter transnacional, facilitado pelas suas origens europeias. A emissão de um segundo passaporte passou a ser visto como fato corriqueiro entre a população de origem europeia do país.

Para a crítica argentina Beatriz Sarlo (2002) essa crise econômica também resultou uma "latino-americanização" social fortíssima, no sentido de que o país começou a se partir em faixas socioeconômicas que antes não se conhecia. Mas, segundo ela, essa "latino-americanização" é somente social e econômica porque não se desenvolveram ainda, formas de sensibilidade cultural em direção a esse ponto.

Numa área conhecida como o "Pátio dos leiteiros" (estação de trem de onde vinha o leite das zonas produtoras do interior do país), o Governo da Cidade de Buenos Aires criou a Feira das Coletividades, permitindo que cada comunidade mostrasse sua gastronomia, artesanato e tradições. Realizada no primeiro domingo de cada mês, a feira recupera uma antiga tradição dos distribuidores de laticínios formados por imigrantes de diferentes países e regiões da Europa tais como a Albânia, Armênia, Baviera (Alemanha), Bielorússia, Croácia, Dinamarca, várias regiões da Espanha e da Itália, Grécia, Irlanda, Líbano, Turquia, Ucrânia, Rússia e Síria. A estes países somaram-se outros da América Latina como Bolívia, Brasil, Colômbia, Cuba, Equador e Venezuela, formando um quadro cultural efetivamente cosmopolita.

Essa feira tem se espalhado por outras cidades do país, fomentada mediante política cultural do governo federal que assume o claro propósito de adequar a sociedade para a interlocução entre a identidade nacional e as matrizes globais da cultura argentina.

\subsection{A "GEOGRAFIA" DA INTEGRAÇÃO BRASILEIRA}

No caso das sociedades integradas etnicamente, está o exemplo brasileiro, visto por Darcy Ribeiro como um modelo original de sociedade nas Américas. Para ele, o fator central que caracteriza a nossa formação étnica é a perspectiva integracionista das raças e culturas que são assimiladas, por ser o país constituído de um povo ainda em formação. A matriz cultural não é regional porque a mestiçagem foi plasmada, indistintamente, em todo o território nacional. Iniciou-se com os caboclos e mulatos lusitanizados pela língua, pela visão de mundo e promovendo, simultaneamente, sua integração na forma de Estado-Nação. Esta forma, segundo ele, já estava madura quando recebeu grande contingente de imigrantes europeus, árabes e japoneses, o que possibilitou ir assimilando todos eles na condição de brasileiros genéricos (RIBEIRO, 1983, p. 448).

Para ele, apesar da má vontade de alguns imigrantes para com o povo original, eles não se constituíram em "enclaves", como se observa em outras sociedades da América. Isso porque os imigrantes não teriam consistência suficiente para se apresentar como uma etnia disputante ao domínio da sociedade.

Sendo uma sociedade singular, fruto da mestiçagem, os brasileiros constituíram-se num dos povos mais homogêneos culturalmente e, também, um dos mais integrados. 
Falam a mesma língua, sem dialetos, e não há sentimentos separatistas fortes. Esta perspectiva integracionista do Brasil, segundo ele, contrasta com os povos testemunhos do México e do Altiplano Andino, e com as sociedades transplantadas dos Estados Unidos, Canadá, Argentina e Uruguai.

Concluindo, argumenta que o Brasil é, portanto, uma sociedade aberta para o futuro cujo principal problema não é a questão étnica ou cultural, mas sim o problema de classe social que nos ligam com o passado colonial, opondo ricos e pobres, opressores e oprimidos (RIBEIRO, 1983, p. 449). Obviamente, que esta visão também pode ser vista como extremamente idealizada, porque as estatísticas sociais mostram que a integração social, pelos menos no mercado de trabalho, ainda é bem restrita para os grupos étnicos chamados de minoritários (índios e negros). Sob estes fatos, o Brasil pode ser apontado como bom exemplo de que evitar a categoria racial para entender a sociedade nacional pode, às vezes, permitir que o racismo continue com força total sem os termos de sua crítica, fazendo valer o chamado "racismo cordial", praticado livremente no país.

Na interpretação de Darcy Ribeiro, mesmo nesta questão, a ideia de sociedade aberta atribuída ao Brasil impede uma exacerbação das segmentações étnicas porque a característica marcante do Brasil em relação aos outros países do continente é a ausência de uma cultura étnica dominante. Em contrapartida, a miscigenação étnica e racial, plasmadando-se em todo o território nacional, surge como fator preponderante na integração nacional. Por essa razão, é o Brasil uma nação geográfica por excelência.

\section{CONCLUSÃO}

Como conclusão, podemos destacar alguns pontos que parecem relevantes para um melhor enquadramento da problemática em questão, a saber, a perspectiva de buscar a unidade continental, respeitando-se a diversidade regional sociopolítica como um grande desafio para todos os povos da América. O fator persistente ainda é o propalado "interesses irreconciliáveis" que se manifesta tanto na frente continental quanto no âmbito nacional de cada um dos países destacados neste estudo.

No plano continental, as duas frentes históricas do movimento de unidade do continente, o monroismo e o bolivarianismo, têm se manifestado de forma contundente na atualidade. Ambas combinam-se e contrapõem-se, apontando para um projeto de unidade com restrições em função do conteúdo das propostas. Os Estados Unidos, insistentes em sua missão de integrar comercialmente os países do continente, erguem, ao mesmo tempo, um muro na fronteira com o México para impedir a entrada de imigrantes latino-americanos. De outro lado, o movimento bolivariano e seu projeto de unificar os povos da América Hispânica, como meio de resgatar a dívida social das populações indígenas e mestiças que estiveram sempre marginalizadas do processo de desenvolvimento econômico.

O advento de organizações regionais na América Latina, como a ALBA, significa, ao mesmo tempo, aspecto importante da diversidade regional no continente, mas também formas de resistências às tentativas de Washington de impor uma única pauta diplomática no âmbito das relações interamericanas, geralmente, convergindo para seus próprios interesses. Quando estes interesses são desafiados, implementam-se sanções. 
Em 9 de março de 2015, quase três meses depois do anúncio do reatamento com Cuba, o presidente Obama anunciou sanções contra autoridades venezuelanas, acusando-as de violações de direitos humanos. Em ordem executiva, a Casa Branca se disse profundamente preocupada com a intimidação de opositores políticos, por parte do governo venezuelano e declarou a Venezuela uma "ameaça à segurança nacional" americana. As sanções confirmariam a Venezuela como "o adversário primário" dos EUA no continente, substituindo Cuba. Ao eleger a Venezuela como seu principal opositor no continente, os EUA favorecem o confronto direto com o grupo de países organizados em torno da ALBA, da qual o governo venezuelano é a principal liderança.

No plano interno das sociedades americanas, observa-se a mesma dificuldade em buscar o consenso, por conta da forte pressão exercida pelos grupos sociais contrários às políticas dos governos eleitos. No Brasil, Argentina, Chile e Venezuela, as forças de oposição têm criado sérios problemas de governabilidade, colocando em risco a continuidade dos programas sociais que tem sido a marca dos atuais governos. Nos Estados Unidos, a expectativa gerada pela construção de uma ordem social pós-racial inaugurada com a eleição de Obama, caracterizada pela rejeição às práticas discriminatórias e divisões raciais que até então caracterizavam a vida política e social do país, tem sido duramente solapada pelos crescentes incidentes raciais, envolvendo o assassinato de membros da comunidade negra em várias cidades do país (ASSIS, 2013).

Como ponto final, gostaríamos de registrar que esse exercício de regionalização do continente americano tem por objetivo, não só compreender o conteúdo histórico e cultural das diferenciações regionais, mas também como meio de entender os discursos e projetos voltados para a integração continental. Em todos, há um elo comum que é a busca da unidade na diversidade, considerando que esta última comporta distintas expressões sociais, políticas e culturais.

\section{BIBLIOGRAFIA}

ALEIXO, José Carlos Brandi Aleixo. O Brasil e o Congresso Anfictiônico do Panamá. Revistabrasileira de política internacional, Brasília, v. 43, n. 02, 2000.

ALVESJUNIOR, Alexandre Guilherme da Cruz. Outras visões: A participação do Secretário de Estado Norte-Americano Elihu Root na III Conferência Interamericana. Boletim do Tempo, v. 05, n. 30, 2010. ASSIS, Mariana. Estados Unidos: a pós-racialidade é um mito. Outras palavras. Comunicação Compartilhada e pós-capitalismo, São Paulo, 24 de julho de 2013. Disponível em: <http://outraspalavras. net/posts/eua-a-pos-racialidade-e-um-mito/24/07/2013 > . Acesso em: 29 maio 2015.

BOLÍVAR, Simón. Carta da Jamaica. In: El Historiador, SD. Disponível em: <http://www.elhistoriador.com.ar/documentos/independencia/bolivar_carta_jamaica.php.>. Acesso em: 15 maio 2015.

BOSI, Alfredo. O nacional, artigo indefinido. Folha de São Paulo, 10 de maio de 1981. Folhetim (acervo on-line). Disponível em: <http://almanaque.folha.uol.com.br/bosil.htm.>. Visualizado em: 10 maio 2015.

CUCCIOLETTA, Donald. L, Américanité et les Amérique. Sainte-Foy. Québec: Presses del'Univeristé Laval, 2001.

DE LUCA, Thania Regina de. A Revista do Brasil: um diagnóstico para a nação. São Paulo: Editora Unesp, 1999. 
FREITAS, Marcos Luã de. Etnicidade, identidade e movimento indígena boliviano contemporâneo. In: Encontro Internacional Fronteiras e Identidades, 2012, Pelotas/MG. Encontro Internacional Fronteiras e Identidades: Caderno de Resumos. Pelotas: Editora da UFPel, 2012. Disponível em: $<$ http://www.academia.edu/2038277/Etnicidade_identidade_e_movimento_indígena_bolivianocontemporâneo>. Acesso em: 05 maio 2015.

FREYRE, Gilberto. Americanidade e latinidade da América Latina: crescente interpretação e decrescente segregação. In: FONSECA, Edson Nery da. Americanidade e latinidade da América Latina e outros textos afins. Brasília: Editora da UnB; São Paulo: Imprensa Oficial do Estado, 2003.

HALL, Stuart. A identidade cultural na pós-modernidade. Rio de Janeiro: DP \& A Editora, 1999.

LÊNIN, Wladimir Iliych. As três fontes e as três partes constitutivas do marxismo. In: Marxists, SD. Disponível em: <https://www.marxists.org/portugues/lenin/1913/03/tresfont.htm.>. Acesso em: 29 de maio de 2015.

MENEZES, Wagner. A contribuição da América Latina para o direito internacional: o princípio da solidariedade. 2007,342 p. (Tese de doutorado). Programa Interunidades de Integração na América Latina, Universidade de São Paulo. São Paulo.

ORTIZ, Renato. Cultura, Modernidade e Identidade. In: SCARLATO et al. Globalização e Espaço Latino-Americano. São Paulo: Hucitec-Anpur, 1993.

PATTEE, Fred Lewis (Editor). The poems of Philip Freneau. Poet of the American revolution. Princeton: Princeton Historical Association, 1902.

PECEQUILO, Cristina Soreanu. A Política Externa dos Estados Unidos: Continuidade ou Mudança. Porto Alegre: Editora da UFRGS, 2003.

PINHEIRO, Marcos Sorrilha. Thomas Jefferson: escravidão e liberdade na independência do Haiti (1791-1806). In: XI Encontro Internacional da Anphlac. Niterói, Anais XI Encontro Internacional Anphlac, 2014.

PRADO, Maria Ligia. América Latina: Tradição e crítica. Revista Brasileira de História, São Paulo, v. 01, n. 02, p. 167-174, 1981.

RIBEIRO, Darcy. As Américas e a Civilização. Petrópolis: Vozes, 1983.

SANTOS, Luís Cláudio Villafañe. A América do Sul no discurso diplomático brasileiro. Brasília: FUNAG, 2014.

SARLO, Beatriz. Beatriz Sarlo: uma voz argentina (Entrevista). Revista Veredas, Rio de Janeiro, v. 07, n. 75, p. 14-19, 2002. Disponível em: <http://www.globalizacion.org/entrevistas/SarloArgentina. htm>. Acesso em: 18 maio 2015.

SMITH, Antony. Para uma cultura global? In: FEATHERSTONE, Mike (org.) Cultura Global. Petrópolis: Vozes, 1994.

TURNER, Frederick Jackson. The frontier in American history. New York: Dover Publications, 1996.

ZARUR, George. Nação e Multiculturalismo em Cuba: uma comparação com os Estados Unidos e o Brasil, 2005. Disponível em: <www.georgezarur.com.br.>. Acesso em: 15 maio 2015. 